\title{
The Role of Technological Innovation in the Effective Economic Performances of Enterprises
}

\author{
Iqboljon Odashev Mashrabjonovich
}

\author{
Leading Specialist, \\ Institute of Forecasting and Macroeconomic Research
}

Creating an environment of innovation in the outlook of our people is our most important task. Without innovation, there will be no competition, no development - Shavkat Mirziyoev, President of the Republic of Uzbekistan

\begin{abstract}
At present, numerous approaches have been verified and suggested in relation to the innovation policy formulation of enterprise. However, less attention is paid to regions in developing world. An attempt is made in this thesis towards that direction. I argue that from system of innovation theory perspective, innovation policy practice for regions in developed world is a problem solving based process, due to the path dependency of innovation policy and the development level of advanced economies. By this purpose, the article proves the possibility of every company's making much more profit by realizing and improving effective innovative management in the developing economy. And, it will be calculated and assessed the correlation link between the costs of innovation and total revenues of the world's most innovative companies. At the end it will be done some conclusions and discussions of nowadays innovators practice.
\end{abstract}

Keywords: Innovation, management, correlation, observes, technological

\section{Introduction}

Innovation is now widely recognized as a central driver of economic growth and development. But in the history of humanity has also shown that human society's interest in news has always been uninterrupted. From the discovery of stone tools to hunting, motifs, clothing, housing, paper and writing, without fear, the historical roots of today's innovation can be called, or rather, the golden era of innovation.

Considering 21 century as the most prosperous period of scientific discoveries in human society, there is no limit to the number of innovations that have been created, discovered and implemented in everyday life. Nonetheless, the main purpose of innovation is to improve the overall well-being of society and the rational use of natural resources. In this regard, the need to form comparative models based on economic analysis of the impact of innovation on the economy and its contribution to the development of each country is one of the most interesting and urgent issues facing economists today.

Is success only about innovation? Innovation is nothing without a winning brand strategy. Innovators who do not get the branding right will not be successful. They run the risk that what is new will be replaced by something more unique if they do not create a compelling brand story. Almost weekly I get a "suggested post" on e-mail, web sites, about something new and fancy, maybe a new wearable, a new smart home device, a new gadget, a new app and so on. All seemingly innovative. One thing many of those posts have in common is that I practically never hear about the new fancy "breakthrough" product again.

The role of discovery is enormous. It enables the invention of new products; it increases productivity, efficiency, and precisions and creates a condition for continuous improvement of innovation. Technological innovation plays a central role in economic growth. A change in technology provides incentive for continued capital accumulation and, in turn, accounts for much of the increase in output.

The positive relationship between technological innovation (TI) and economic growth has long been identified in formal growth models (Kydland and Prescott, 1982; Romer, 1990; Solow, 1956, 1957). The neoclassical growth model of Solow $(1956,1957)$ recognizes technical change as an exogenous variable that plays a critical role in long-run economic growth. Arrow (1962) acknowledges that a constant growth of technology, apart from the quality of labor force, has a crucial impact on long-term economic growth. Other scholars, including Uzawa (1965), Phelps (1966), Conlisk (1967; 1969), and Shell (1967), provide enormous insights on the wider role of technological innovation in economic growth, competitiveness, employment, and productivity of nations. The recent past models of endogenous growth by Romer (1990), Grossman and Helpman (1991), Grossman (1993), and Aghion and Howitt (1992) have shown that allocating resources for generation of new technologies or innovation leads to a continuous rise in the economic growth of nations. It then goes without saying that the production and application of technology in regions will not only bring about different level of economic and noneconomic advancements but will also have considerable effects on future income differences and development of the regions.

The purpose of the article is to analyze the role of technological innovations in market economy through practical examples and to summarize the results and to identify the main areas of innovation that are relevant to the development of economy of Uzbekistan, to give an objective assessment of all its elements.

A number of effective reforms are being carried out in our country to promote promising research and innovation activities, to develop effective mechanisms in this area, to strengthen scientific-experimental specialized laboratories, hi-tech centers, technology parks and other innovative 


\section{International Journal of Science and Research (IJSR) \\ ISSN: 2319-7064}

ResearchGate Impact Factor (2018): 0.28 | SJIF (2018): 7.426

structures. By the initiative of the President of the Republic of Uzbekistan, consistent work is underway in the country on innovative development of leading industries and sectors, broad introduction of innovative ideas and technologies into production. Presidential Decree of November 29, 2017 "On the establishment of the Ministry of Innovative Development of the Republic of Uzbekistan" promotes the work in this area to a new level.

The country is characterized by the innovative attractiveness of enterprises and organizations in which innovation is introduced into the economy.

In many cases, the only successfulness of an innovative business can be successful business entities. But how to keep that success or how to achieve it again and again, is particularly relevant.

That is why businesses and organizations often face such issues as:

$>$ How can be more innovative in innovation world?

$>$ How to build a new business order and process?

$>$ How to build a business strategy to counter business uniformity?

$>$ How to build an "innovative culture" in governance?

Continuing successful business in the long run will require creativity that will enable new growth businesses. At the same time, businesses and organizations need to create an "Innovative Genius", which, at the moment, can be the basis of another new business.

\section{Methods and Resultation}

We will directly evaluate the economic value and financial effectiveness of innovation using the following practical examples.

Example № 1. Lenovo Group Limited is one of the world's leading multinational companies that produce a wide range of products such as computers, laptops, smartphones and more. The company's mission is "New World. New Thinking", which perfectly explains its management philosophy. The company has a number of factories in the US, Europe, India and Mexico. According to Forbes magazine, in 2011 Lenovo was included in the list of the ten most ecologically clean companies. The company is also ranked among the top 50 employers, according to an analysis by Universum, a leading research institute.

In assessing the effectiveness of investment in innovation, we analyze the correlation link between the costs of this company for the period from 2010 till 2018 and its profits over that period using a linear regression equation step-bystep [11]:

Table 1: Lenovo Group Limited's expenditures on development programs and revenues for the period from 2010 till 2018

\begin{tabular}{|c|c|c|c|c|c|c|c|c|}
\hline Periods & $\mathbf{2 0 1 0} / \mathbf{1 1}$ & $\mathbf{2 0 1 1 / 1 2}$ & $\mathbf{2 0 1 2} / \mathbf{1 3}$ & $\mathbf{2 0 1 3} / \mathbf{1 4}$ & $\mathbf{2 0 1 4} / \mathbf{1 5}$ & $\mathbf{2 0 1 5 / 1 6}$ & $\mathbf{2 0 1 6 / 1 7}$ & $\mathbf{2 0 1 7 / 1 8}$ \\
\hline Total Revenue (Y) & 21.6 & 29.6 & 33.9 & 38.7 & 46.3 & 44.9 & 43.0 & 45.4 \\
\hline R\&D Expense (X) & 0.30 & 0.45 & 0.62 & 0.73 & 1.22 & 1.49 & 1.36 & 1.27 \\
\hline
\end{tabular}

Earnings for the selected periods are random because they are variables. It is represented by the random variables of the regression equation $\mathbf{a}$ and $\mathbf{b}$, which is estimated by using the equation to explain how the innovation costs have a correlation dependence.

We use the least-squares method to evaluate the parameters a and b. The least-squares method allows for estimating the parameters of the regression equation more accurately. Here's how to use the least-squares method:

$$
\mathrm{S}=\sum\left(x_{i}-y_{i}\right)^{2} \rightarrow \min
$$

The equation looks like this:

$$
\left\{\begin{array}{c}
a \cdot \mathbf{n}+\mathbf{b} \cdot \sum \mathbf{x}=\Sigma \mathbf{y} \\
\mathbf{a} \cdot \sum \mathbf{x}+\mathbf{b} \cdot \sum \mathbf{x}^{2}=\Sigma \mathbf{y} \cdot \mathbf{x}
\end{array}\right.
$$

Now, to determine the specific parameters of this equation, we perform the calculations in the following table:

\begin{tabular}{|c|c|c|c|c|}
\hline $\mathbf{x}$ & $\mathbf{y}$ & $\mathbf{x}^{\mathbf{2}}$ & $\mathbf{y}^{\mathbf{2}}$ & $\mathbf{x} \cdot \mathbf{y}$ \\
\hline $\mathbf{0 . 3}$ & $\mathbf{2 1 . 6}$ & 0.09 & 466.56 & 6.48 \\
\hline $\mathbf{0 . 4 5}$ & $\mathbf{2 9 . 6}$ & 0.2025 & 876.16 & 13.32 \\
\hline $\mathbf{0 . 6 2}$ & $\mathbf{3 3 . 9}$ & 0.3844 & 1149.21 & 21.018 \\
\hline $\mathbf{0 . 7 3}$ & $\mathbf{3 8 . 7}$ & 0.5329 & 1497.69 & 28.251 \\
\hline $\mathbf{1 . 2 2}$ & $\mathbf{4 6 . 3}$ & 1.4884 & 2143.69 & 56.486 \\
\hline $\mathbf{1 . 4 9}$ & $\mathbf{4 4 . 9}$ & 2.2201 & 2016.01 & 66.901 \\
\hline $\mathbf{1 . 3 6}$ & $\mathbf{4 3 . 0}$ & 1.8496 & 1849.00 & 58.48 \\
\hline $\mathbf{1 . 2 7}$ & $\mathbf{4 5 . 4}$ & 1.6129 & 2061.16 & 57.658 \\
\hline $\mathbf{7 . 4 4}$ & $\mathbf{3 0 3 . 4}$ & $\mathbf{8 . 3 8 0 8}$ & $\mathbf{1 2 0 5 9 . 4 8}$ & $\mathbf{3 0 8 . 5 9 4}$ \\
\hline
\end{tabular}

According to these data, the system of equations we need is as follows:

$$
\left\{\begin{array}{c}
a+7.44 \cdot b=303.4 \\
7.44 \cdot a+8.381 \cdot b=308.594
\end{array}\right.
$$

Volume 8 Issue 12, December 2019

www.ijsr.net

Licensed Under Creative Commons Attribution CC BY 
By solving the system of equations, we obtain the empirical coefficients of the regression equation $\mathbf{a}=$ 21.1066, $\mathbf{b}=\mathbf{1 8 . 0 8 4 3}$. We can describe the regression equation as follows:

$$
Y=18.0843 X+21.1066
$$

\section{Parameters of the regression equation:}

\section{Medium units:}

$$
\begin{aligned}
& \overline{\boldsymbol{x}}=\frac{\sum x_{i}}{n}=\frac{7.44}{8}=0.93 \\
& \overline{\boldsymbol{y}}=\frac{\sum y_{i}}{n}=\frac{303.4}{8}=37.925 ; \\
& \overline{\boldsymbol{x} \boldsymbol{y}}=\frac{\sum x_{i} y_{i}}{n}=\frac{308.59}{8}=38.574 .
\end{aligned}
$$

Sample dispersion:

$$
\begin{aligned}
& \mathbf{S}^{2}(\mathbf{x})=\frac{\sum_{x_{i}}{ }^{2}}{n}-\bar{x}^{2}=\frac{8.38}{8}-0.93^{2}=0.18 ; \\
& \mathbf{S}^{2}(\mathbf{y})=\frac{\sum_{y_{i}}{ }^{2}}{n}-\bar{y}^{2}=\frac{12059.48}{8}-37.925^{2}=69.13 ;
\end{aligned}
$$

\section{Covariation.}

$$
\operatorname{cov}(x, y)=x \cdot y-x \cdot y=38.574-0.93 \cdot 37.925=3.3 .
$$

\section{Medium units: Sample dispersion:}

\section{Covariation.}

We now calculate the dependency strength of the parameters. For this we use the correlation coefficient of the linear regression equation. It is calculated as follows:

$$
\begin{aligned}
& 0.1<\mathrm{r}_{\mathrm{xy}}<0.3 \text { : the weakest; } \\
& 0.3<\mathrm{r}_{\mathrm{xy}}<0.5 \text { : weak; } \\
& 0.5<\mathrm{r}_{\mathrm{xy}}<0.7 \text { : higher; }
\end{aligned}
$$

In our example, the correlation between the parameters $\mathrm{Y}$ and $X$ is high and direct. Because, $0.9<0.93<1$.

\section{Let us evaluate the significance of the correlation coefficient:}

$\mathrm{H}_{0}: \mathrm{r}_{\mathrm{xy}}=0$, there is no linear relationship between variables;

$\mathrm{H}_{1}: \mathrm{r}_{\mathrm{xy}} \neq 0$, there is a linear relationship between the variables.

When evaluating the significance of the correlation coefficient, one of the following inequalities should be satisfied:

The first hypothesis is correct if $\mathbf{t}_{\text {observed point }}<\mathbf{t}_{\text {critical point }}$ inequality among variables is satisfied, The second hypothesis is correct if $\left|\mathbf{t}_{\text {observed }}\right|>\mathbf{t}_{\text {critical point }}$ inequality among variables is satisfied.

Here $\mathbf{t}_{\mathbf{o b s e r v}}=\mathbf{r}_{\mathrm{xy}} \frac{\sqrt{\boldsymbol{n}-\mathbf{2}}}{\sqrt{\mathbf{1 - r _ { x y } ^ { 2 }}}}$, is calculated by this formulation and is equal to:

$$
\mathrm{t}_{\text {observ }}=0.93 \frac{\sqrt{6}}{\sqrt{1-0.93^{2}}}=6.183 \text {. }
$$

When $\boldsymbol{\alpha}=\mathbf{0 . 0 5}$ and the degree of freedom $\mathbf{k}=\mathbf{6}$, according to the student series, $\mathbf{t}_{\text {critical point }}$ is equal to:

$$
\mathrm{r}_{\mathrm{xy}}=\frac{\overline{x y}-\bar{x} * \bar{y}}{S(x) * S(y)}=\frac{38.574-0.93 * 37.925}{0.427 * 8.314}=0.93
$$

The linear correlation coefficient is calculated between -1 and +1 . The relationship between the factors may be weak or strong. The Cheddoka scale is used to evaluate its criteria with greater accuracy:

$$
\begin{aligned}
& 0.7<\mathrm{r}_{\mathrm{xy}}<0.9 \text { : great; } \\
& 0.9<\mathrm{r}_{\mathrm{xy}}<1 \text { : the greatest. }
\end{aligned}
$$

$$
t_{\text {critical }}(n-m-1 ; \alpha / 2)=(6 ; 0.025)=2.447
$$

Where $\mathbf{m}$ is the number of variables explained.

Thus, we can conclude that the correlation coefficients in our sample are significant and statistically significant. Because,

$$
\left|t_{\text {observ }}\right|>t_{\text {critical point, }}|6.183|>2.447 \text {. }
$$

By this small experience, we can conclude that Lenovo Group Limited has a direct and indirect relationship with the increased revenues of innovation over the years. This correlation is reflected in the correlation coefficient $\mathbf{r}_{\mathbf{x y}}=\mathbf{0 . 9 3}$ and it is also possible to conclude that, in terms of scientific significance, there is a linear relationship between $\mathbf{H}_{\mathbf{1}}: \mathbf{r}_{\mathbf{x y}} \neq \mathbf{0}$, that is, variables.

Many experiments were calculated directly from the world's most innovative corporations such as Apple Inc., Microsoft Corporation, Amazon.com, Inc., Alphabet Inc., Volkswagen Aktiengesellschaft, Johnson \& Johnson, and the following scientific conclusions were made:

Example № 2. For Apple Inc., the linear regression equation $\mathbf{y}=\mathbf{1 8 . 4 1 8 7} \mathbf{x}+\mathbf{4 4 . 3 8 7 2}$ the period from 2012 till 2018 innovation costs and revenues is based on the following table [10]: 


\title{
International Journal of Science and Research (IJSR) \\ ISSN: 2319-7064
}

ResearchGate Impact Factor (2018): 0.28 | SJIF (2018): 7.426

Table 2: Apple Inc., expenditures on development programs and revenues for the period from 2012 till 2018

\begin{tabular}{|c|c|c|c|c|c|c|c|}
\hline Apple Inc. & 2012 & 2013 & 2014 & 2015 & 2016 & 2017 & 2018 \\
\hline $\begin{array}{c}\text { R\&D Expense (in USD billions, income statement } \\
\text { exchange rate) }\end{array}$ & 2,43 & 3,38 & 4,48 & 6,04 & 8,07 & 10,05 & 11,58 \\
\hline $\begin{array}{c}\text { Total Revenue (in USD billions, income statement } \\
\text { exchange rate) }\end{array}$ & 108,25 & 156,51 & 170,91 & 182,80 & 233,72 & 215,64 & 229,23 \\
\hline
\end{tabular}

Medium size:

$$
\begin{aligned}
& \bar{x}=\frac{\sum x_{i}}{n}=\frac{63.8}{13}=4.908 \\
& \bar{y}=\frac{\sum y_{i}}{n}=\frac{1752.147}{13}=134.781 ; \\
& \overline{x y}=\frac{\sum x_{i} y_{i}}{n}=\frac{12952.98}{13}=996.383 .
\end{aligned}
$$

The correlation coefficient is,

$$
\mathbf{r}_{x y}=\frac{\overline{x y}-\bar{x} * \bar{y}}{S(x)_{*}(y)}=\frac{996.383-4.908 * 134.781}{4.264 * 85.651}=0.917
$$

Example № 3. For the Microsoft Corporation., the linear regression equation $\mathbf{y}=\mathbf{6 . 5 3 8 2} \times \mathbf{+ 6 . 8 3 2 5}$ for the period from 2012 till 2018 innovation costs and revenues is based on the following table [8]:

Table 3: Microsoft corporation expenditures on development programs and revenues for the period from 2012 till 2018

\begin{tabular}{|c|c|c|c|c|c|c|c|}
\hline Microsoft Corporation & 2012 & 2013 & 2014 & 2015 & 2016 & 2017 & 2018 \\
\hline $\begin{array}{c}\text { R\&D Expense (in USD billions, income } \\
\text { statement exchange rate) }\end{array}$ & $\mathbf{9 , 8 1 1}$ & 10,411 & $\mathbf{1 1 , 3 8 1}$ & $\mathbf{1 2 , 0 4 6}$ & $\mathbf{1 1 , 9 8 8}$ & 13,037 & $\mathbf{1 2 , 2 9 2}$ \\
\hline $\begin{array}{c}\text { Total Revenue (in USD billions, income } \\
\text { statement exchange rate) }\end{array}$ & $\mathbf{6 9 , 9 4 3}$ & $\mathbf{7 3 , 7 2 3}$ & $\mathbf{7 7 , 8 4 9}$ & $\mathbf{8 6 , 8 3 3}$ & $\mathbf{9 3 , 5 8}$ & $\mathbf{8 5 , 3 2}$ & $\mathbf{8 9 , 9 5}$ \\
\hline
\end{tabular}

Medium size:

$$
\begin{aligned}
& \bar{x}=\frac{\sum x_{i}}{n}=\frac{80.966}{7}=11.567 ; \\
& \bar{y}=\frac{\sum y_{i}}{n}=\frac{577.098}{7}=82.443 ; \\
& \overline{x y}=\frac{\sum x_{i} y_{i}}{n}=\frac{6724.32}{7}=960.617 .
\end{aligned}
$$

The correlation coefficient is,

$$
\mathbf{r}_{\mathrm{xy}}=\frac{\overline{x y}-\bar{x} * \bar{y}}{S(x) * S(y)}=\frac{960.617-11.567 * 82.443}{1.038 * 8.105}=0.836
$$

\section{Dispersion:}

$$
\begin{aligned}
& \mathrm{S}^{2}(\mathbf{x})=\frac{\sum_{x_{i}}{ }^{2}}{n}-\bar{x}^{2}=\frac{944.05}{7}-11.567^{2}=1.08 ; \\
& \mathrm{S}^{2}(\mathrm{y})=\frac{\sum_{y_{i}}^{2}}{n}-\bar{y}^{2}=\frac{48037.28}{7}-82.443^{2}=65.69 ;
\end{aligned}
$$

Example № 4. For Amazon.com, Inc. the linear regression equation $\mathbf{y}=\mathbf{6 . 5 0 5 8} \mathbf{x}+\mathbf{2 9 . 7 7 5 8}$ for the period from 2012 till 2018 innovation costs and revenues is based on the following table:

Table 4: Amazon.Inc., expenditures on development programs and revenues for the period from 2012 till 2018

\begin{tabular}{|c|c|c|c|c|c|c|c|}
\hline Amazon.com, Inc. & 2012 & 2013 & 2014 & 2015 & 2016 & 2017 & 2018 \\
\hline $\begin{array}{c}\text { R\&D Expense (in USD billions, income } \\
\text { statement exchange rate) }\end{array}$ & 2,91 & 4,56 & $\mathbf{6 , 5 7}$ & $\mathbf{9 , 2 8}$ & 12,54 & 16,09 & 22,62 \\
\hline $\begin{array}{c}\text { Total Revenue (in USD billions, income } \\
\text { statement exchange rate) }\end{array}$ & $\mathbf{4 8 , 0 8}$ & $\mathbf{6 1 , 0 9}$ & $\mathbf{7 4 , 4 5}$ & $\mathbf{8 8 , 9 9}$ & $\mathbf{1 0 7 , 0 1}$ & $\mathbf{1 3 5 , 9 9}$ & $\mathbf{1 7 7 , 8 7}$ \\
\hline
\end{tabular}

\section{Medium size:}

$$
\begin{aligned}
& \overline{\boldsymbol{x}}=\frac{\sum x_{i}}{n}=\frac{74.57}{7}=10.653 ; \\
& \overline{\boldsymbol{y}}=\frac{\sum y_{i}}{n}=\frac{693.57}{7}=99.081 ; \\
& \overline{\boldsymbol{x} y}=\frac{\sum x_{i} y_{i}}{n}=\frac{9287.98}{7}=1326.854 .
\end{aligned}
$$

The correlation coefficient is,

$$
\mathbf{r}_{\mathrm{xy}}=\frac{\overline{x y}-\bar{x} * \bar{y}}{S(x) * S(y)}=\frac{1326.854-10.653 * 99.081}{6.458 * 42.067}=0.999 .
$$

Example № 5. For Alphabet Inc., the linear regression equation $\mathbf{y}=\mathbf{6 . 1 4 1 2} \mathbf{x}+\mathbf{6 . 1 7 6}$ for the period from 2012 till

\section{Dispersion:}

$\mathrm{S}^{2}(\mathbf{x})=\frac{\sum_{x_{i}}{ }^{2}}{n}-\bar{x}^{2}=\frac{1086.35}{7}-10.653^{2}=41.71 ;$

$\mathrm{S}^{2}(\mathbf{y})=\frac{\sum_{y_{i}}^{2}}{n}-\bar{y}^{2}=\frac{81107.12}{7}-99.081^{2}=1769.6$;

2018 innovation costs and revenues is based on the following table:

\section{Volume 8 Issue 12, December 2019}

\author{
www.ijsr.net
}




\section{International Journal of Science and Research (IJSR) \\ ISSN: 2319-7064}

ResearchGate Impact Factor (2018): 0.28 | SJIF (2018): 7.426

Table 5: Alphabet Inc., expenditures on development programs and revenues for the period from 2012 till 2018

\begin{tabular}{|c|c|c|c|c|c|c|c|}
\hline Alphabet Inc. & 2012 & 2013 & 2014 & 2015 & 2016 & 2017 & 2018 \\
\hline $\begin{array}{c}\text { R\&D Expense (in USD billions, income statement } \\
\text { exchange rate) }\end{array}$ & 5,16 & 6,79 & 7,14 & $\mathbf{9 , 8 3}$ & 12,28 & 13,95 & 16,23 \\
\hline $\begin{array}{c}\text { Total Revenue (in USD billions, income statement } \\
\text { exchange rate) }\end{array}$ & 37,91 & 46,04 & $\mathbf{5 5 , 5 2}$ & 66,00 & 74,99 & 90,27 & 110,86 \\
\hline
\end{tabular}

Medium size:

$\overline{\boldsymbol{x}}=\frac{\sum x_{i}}{n}=\frac{71.38}{7}=10.197$;

$\bar{y}=\frac{\sum y_{i}}{\eta}=\frac{481.59}{7}=68.799$;

$\overline{\boldsymbol{x y}}=\frac{\sum x_{i} y_{i}}{n}=\frac{5532.82}{7}=790.403$

\section{Dispersion:}

$\mathrm{S}^{2}(\mathbf{x})=\frac{\Sigma_{x_{i}}{ }^{2}}{n}-\bar{x}^{2}=\frac{829.15}{7}-10.197^{2}=17.47$

$\mathrm{S}^{2}(\mathbf{y})=\frac{\sum_{y_{i}}^{n}}{n}-\bar{y}^{2}=\frac{37057.43}{7}-68.799^{2}=560.68$;

The correlation coefficient is,

$$
\mathbf{r}_{\mathrm{xy}}=\frac{\overline{x y}-\bar{x} * \bar{y}}{S(x) * S(y)}=\frac{790.403-10.197 * 68.799}{3.804 * 23.679}=0.987
$$

Table 6: The linear regression equations and levels of correlation between expenditures and revenues of the world's five the biggest innovators for the period from 2012 till 2018 [16]

\begin{tabular}{|c|c|c|c|c|}
\hline Lenovo Group Limited & Apple Inc. & Microsoft Corporation & Amazon.com, Inc & Alphabet Inc. \\
\hline$Y=18.1 X+1.1$ & $Y=18.4 x+44.4$ & $Y=6.53 x+6.9$ & $Y=6.51 x+29.8$ & $Y=6.14 x+6.2$ \\
\hline $\begin{array}{c}r_{x y}=0.930 .9<r_{x y}<1 \\
\text { the greatest, direct }\end{array}$ & $\begin{array}{c}\mathrm{r}_{\mathrm{xy}}=0.917 \\
0.9<\mathrm{r}_{\mathrm{xy}}<1 \text { the } \\
\text { greatest, direct }\end{array}$ & $\begin{array}{c}r_{x y}=0.836 \\
0.7<r_{x y}<0.9 \\
\text { great, direct }\end{array}$ & $\begin{array}{c}\mathrm{r}_{\mathrm{xy}}=0.999 \\
0.9<\mathrm{r}_{\mathrm{xy}}<1 \text { the } \\
\text { greatest, direct }\end{array}$ & $\begin{array}{c}r_{x y}=0.987 \\
0.9<r_{x y}<1 \text { the } \\
\text { greatest, direct }\end{array}$ \\
\hline
\end{tabular}

As we observe the day-by-day financial management of these innovative companies, we find that these companies' expertise in the rational use, creation, and implementation of innovations differ from each other, and have different strategic solutions within their mission. But correlation link between $R \& D$ expenses and total revenues high and direct.

There is also a globally accepted set of rules and principles that are proposed to be implemented in the management of companies, regardless of the type of activity.

One of the most famous of these is the principle of "7 Strategy"[13]:

1) Formation of a specific direction of innovation.

2) Creating an environment of trust and open communication between management and employees.

3) Reduce the level of formalism.

4) Ensure employees have a stake in the workplace.

5) Recognize that innovation skills are recognized and rewarded.

6) Resilience in the face of risk and failure.

7) Identifying ineffective projects and processes will ensure innovation sustainability in enterprises and organizations.

Each section of the Strategic Seven reflects a particular problem, introduces them to the management process, and makes the following suggestions and conclusions:

- Conduct discussions with project managers on eliminating the existing constraints on the organization;

- Develop a program to identify potential factors that impede the implementation of the existing innovation process;
- Categorize resources for business innovation by the level of business activity;

- Conducting investment policy with respect to profitability;

- Acquaintance with the results of measures taken on similar issues in other organizations to improve the innovation efficiency of enterprises and organizations and to receive recommendations from other research developments;

- Leadership culture, experience sharing, and retraining of personnel along with the practice of projects implemented in the organization.

\section{Conclusion and Discussion}

Comfort is not an option if organizations want to be comfortable with their innovation results. Comfort is not an option when brands want to outperform strong peers. Comfort is not an option if teams want to survive. Innovation is never imitation. The ultimate decisionmaking bodies are consumers voting with their wallets. As a consequence, we should treat new ideas as innovation only if they resonate with consumers and if they are genuinely new in their eyes, make their lives easier in a relevant, insightful, exciting and different way. All of this should take place in the eyes of the consumer, not just by internal standards.

Innovation is the responsibility of top management, and the responsibility cannot be delegated. It is not enough to demand that teams come up with innovative products. A demanding innovation culture has to be embedded in the organization from top management throughout all levels.

The fundamental questions are: does what we do really make the lives of consumers easier? Is it really different?

\section{Volume 8 Issue 12, December 2019}




\section{International Journal of Science and Research (IJSR) \\ ISSN: 2319-7064}

ResearchGate Impact Factor (2018): 0.28 | SJIF (2018): 7.426

Is it really new? Is it really relevant for many? Is it exciting enough? If just one of these questions cannot be answered with a clear yes then failure is predictable. If there is one no, even a maybe, it is better to rework an idea again and again until a maybe becomes a yes. And if after ten, 20 or even 100 revisions it is still not a yes, then it is a no.

Innovation has to fit and strengthen the brand. The brand cannot be the afterthought but needs to be the central consideration. What works for brand A probably does not work for brand B. Breakthrough technology is where many branding mistakes are made. Being so busy with bringing seemingly disruptive technology to life, companies do not pay enough attention to the brand under which they will sell the technology. They forget that the brand is everything, that a very well-defined brand will outlast the technology and that the technology itself will be obsolete the moment a better solution comes to the market.

R\&D outlay includes the total amount of capital invested for any kind of research and development related activities, regardless of whether the expenditure is made in private, public, or university organization. $R \& D$ outlay and intramural $\mathrm{R} \& \mathrm{D}$ expenditures are all expenditures for research and development $(\mathrm{R} \& \mathrm{D})$ performed within a statistical unit or sector of the economy during a specific period, whatever the source of funds. The procedure for obtaining intramural $R \& D$ expenditure at a regional level is as follows: first, identify the intramural expenditure on R\&D performed by each statistical unit; second, identify the sources of funds for these intramural $R \& D$ expenditures as reported by the performer; and finally, aggregate the data by region of performance and sources of funds to de-rive significant regional totals to identify the extramural $R \& D$ expenditures of each statistical region. [2]

Many established players do the same-confuse a trademark with a brand, and by this not realize the real growth potential.

Innovation beyond the comfort zone: it requires new thinking-much more holistic, bold, differentiated and consumer-centric, always keeping the point of difference to competition in mind. One is required to say no when the offer is not yet good enough. The time for compromise is over. If your teams are in the comfort zone, the result will not be innovation. Your company may not be around much longer, all because someone else innovated beyond the comfort zone.

\section{References}

[1] Mykhaylo Oystrakh, 2016, The Effect of Technological Innovations on Economic Activity, Waterloo, Ontario, Canada

[2] Soumitra Dutta, Francis Gurry, Bruno Lanvin, 2019, The Global Innovation Index 2019, Geneva, Switzerland the World Intellectual Property Organization (WIPO)
[3] Stefanie Siraghi, 2018, Innovation beyond the comfort zone, 20 Cabot Square London, 2018 The Economist Intelligence Unit Limited

[4] S. Y. Salamatina, №2(5) 2017, Innovative development of the world economy in globalization, Russian Federation, mid-journal, p.121-125

[5] Kashnikova Tatiana Vasilievna, 2017, Borodina Anna Olegovna, Innovative models of economic growth: foreign experience, Problems of economy, p.91-94.

[6] Dudin M.N., Lyasnikov N.V. 2012, Strategic management of innovation development of Russian business structures through the use of foresight, Russian Federation, European journal of natural history, p.30-31

[7] Vasilyeva N.F., Kavura V.L., № (3) 2016, The model of the economy innovative development: international experience of implementation, Russian Federation, The informative press of the Institute of economical research, p. 74-82

[8] https://www.microsoftrnd.co.il/whoweare\#Communit $\mathrm{y}$

[9] https://www.strategyand.pwc.com/gx/en/insights/inno vation1000.html

[10] https://www.macrotrends.net/stocks/charts/AAPL/app le/stock-price-history

[11] https://www.macrotrends.net/stocks/charts/LNVGY/l enovo-group/revenue

[12] https://scienceproblems.ru/nauchnaja-statja/

[13] http://www.sciencepublishinggroup.com/common/

[14] http://atlas.cid.harvard.edu/rankings

[15] https://www.statista.com/

[16] https://www.strategy-business.com/feature/What-theTop-Innovators-Get-Right?gko=e7cf9

[17] https://math.semestr.ru/corel/corel.php

Volume 8 Issue 12, December 2019

www.ijsr.net

Licensed Under Creative Commons Attribution CC BY 